\title{
In-situ non-destructive analysis of Etruscan gold jewels with the micro-XRF transportable spectrometer from CNA
}

\author{
S. Scrivano ${ }^{\mathrm{a}, \mathrm{b}, *}$, C. Ruberto ${ }^{\mathrm{c}, \mathrm{d}}$, B. Gómez-Tubío ${ }^{\mathrm{a}, \mathrm{e}}$, A. Mazzinghi ${ }^{\mathrm{c}, \mathrm{d}}$, I. Ortega-Feliu ${ }^{\mathrm{a}}$, F.J. Ager ${ }^{\mathrm{a}, \mathrm{f}}$, \\ K. Laclavetine ${ }^{\mathrm{a}, \mathrm{b}}$, L. Giuntini ${ }^{\mathrm{c}, \mathrm{d}}$, M.A. Respaldiza ${ }^{\mathrm{a}, \mathrm{b}}$ \\ a Centro Nacional de Aceleradores (CNA) (Universidad de Sevilla, CSIC, Junta de Andalucía), C/ Thomas A. Edison 7, Seville, E-41092, Spain \\ b Departamento de Física Atómica, Molecular y Nuclear, Universidad de Sevilla, Av/Reina Mercedes s/n, Seville E-42012, Spain \\ c Istituto Nazionale di Fisica Nucleare (INFN), Sezione di Firenze, Via Sansone 1, Sesto Fiorentino, Florence, I-50019, Italy \\ d Dipartimento di Fisica e Astronomia, Università di Firenze, Via Sansone 1, Sesto Fiorentino, Florence, I-50019, Italy \\ e Departamento de Física Aplicada III, Universidad de Sevilla, Camino de los Descubrimientos, s/n, Seville E-41092, Spain \\ f Departamento de Física Aplicada I, Universidad de Sevilla, c/ Virgen de Africa 7, Seville E-41015, Spain
}

\section{A R T I C L E I N F O}

\section{Keywords:}

Transportable micro-XRF

Polycapillary optics

Etruscan

Gold jewels

Welding

Soldering

Gold metallurgy

MSC:

00-01

99-00

\begin{abstract}
A B S T R A C T
The study of valuable Cultural Heritage objects frequently requires non-destructive analysis with good sensitivity. Moreover, it is often necessary that the measures are carried out in-situ, in particular when transport of the items from the institutions to the laboratory is not allowed.

In this work, the technical specifications of the micro-XRF spectrometer developed at the CNA in Seville is presented and its analytical capabilities are tested by means of the analysis of a set of Etruscan gold jewels of the National Archaeological Museum of Florence. Since these jewels are characterized by elaborate decorations, with details of typical dimensions down to tens of microns, a high lateral resolution is required to study the features of these objects. The challenge consists in the characterization of the welding/soldering zones and the details of the jewels that present a very complex geometry. This paper shows the micro-XRF in-situ analysis of 15 Etruscan gold jewels (from the VII century BCE) in order to characterize the alloy composition of sheets, threads, filigrees, granules, as well as the joining zones. Based on these results, the manufacture technique and the production process employed by the Etruscan goldsmiths could be described.
\end{abstract}

\section{Introduction}

In the last century, the application of nuclear physics to the study of cultural heritage materials has grown rapidly. The compositional analysis of the materials and the study of ancient human production can help in the conservation, restoration and authentication of the objects (Guerra, 2008) and may provide complementary information about the evolution of the manufacture technology and possible trade relations (Karydas et al., 2004; Tissot et al., 2013). In this framework, techniques such as Particle-Induced X-ray Emission (PIXE), X-ray Fluorescence (XRF) and Scanning Electron Microscope (SEM) have become increasingly important for the analysis of the composition of those valuable artifacts, due to its non-destructive and non-invasive features. Recently, the development of more compact X-ray tubes has provided portable systems useful for the study of objects which cannot be moved to a laboratory, as it is the case of ancient valuable gold jewels that are frequently stored in their safe-keeping sites or displayed in a permanent exhibition. Since jewels are characterized by details of typical dimensions down to tens of microns, a high lateral resolution is necessary to study the soldering technique and the features of the objects (Guerra and Tissot, 2013). In this case, when in-situ analysis is required, micro-XRF can be a valuable alternative (Papadopoulou et al., 2006; Potts, 2008). For this purpose, a transportable micro-XRF set-up developed at CNA (Centro Nacional de Aceleradores, Spain) has been used.

Gold artifacts are excellent objects for the characterization of ancient metallurgical techniques considering that gold work was one of the first metallurgical techniques performed by man, mostly connected with symbols of eternal life and power. In the context of gold jewelry dating back to the first millennium B.C. in the Mediterranean area, the Etruscan artifacts stand out for their fineness and great decorative style expressed by intricate work which involve filigree, granulate and embossed decorations assembled together with several joining techniques (Mello et al., 1983). The complexity of the jewels requires the use of high-quality soldering methods in order to join different decorations. In antiquity, three soldering methods were the most commonly used:

\footnotetext{
"Corresponding author.

E-mail address: simonascrivano@us.es (S. Scrivano).
} 
brazing, solid state diffusion bonding and autogenous welding. The first one employs a lower melting point alloy; the second one consists in the use of a copper salt solution in the joining area; whereas the last one is based on the local heating of the pieces to be soldered without the use of any additional material (Baldini Lippolis and Guaitoli, 2009; Echt and Thiele, 1993; Mathot and Demortier, 2004; Nestler and Formigli, 1994; Scrivano et al., 2013). These methods could be used separately or combined in the same jewel, depending on the size of the decoration to be joined and the skill of the goldsmiths (Ferro et al., 2009).

In this article the transportable micro-XRF set-up is outlined and the analytical characteristics of the instrument are presented. This device has been developed for the optimization of the analysis applied to Cultural Heritage materials, satisfying aspects related to the safety of the objects, the quality and the speed of the measurements. Furthermore, the in-situ analytical capabilities of the instrument are illustrated in the reference frame of the study of a set of 15 gold jewels belonging to the Etruscan Orientalizing period from the collection of the National Archaeological Museum of Florence. The transportable micro-XRF spectrometer allows for the characterization of the composition of the alloys, of the soldering methods employed for the manufacture of those Etruscan jewels and successfully provides information about authentication issues.

\section{Instrument characteristics}

\subsection{Description of the set-up}

The transportable micro-XRF set-up consists of a three-axis motor stage from STANDA Ltd. ( $\approx 1 \mu \mathrm{m}$ full-step resolution) coupled with a horizontal platform and a fixed measuring head mounted on a horizontal telescopic tripod structure (dimension: $60 \mathrm{~cm} \times 40 \mathrm{~cm}$, total weight of the system: $\approx 45 \mathrm{~kg}$ ). This stage has been specifically designed for the easy positioning of ancient archaeological objects in front of the beam. Indeed, the Etruscan gold jewels studied cannot be placed in a vertical position or suspended in front of the beam. A system of spirit levels fixed on the different axis of the set-up permits to check the horizontality of the structure.

The measuring head consists of a low power $(30 \mathrm{~W})$ air-cooled microfocus X-ray tube (iMOXS, IFG Institute for Scientific Instrument, Berlin, Germany) with $\mathrm{Rh}$ anode $(50 \mathrm{kV}, 0.6 \mathrm{~mA})$ coupled with a Fulllens policapillary (115mls03 model, $50 \mu \mathrm{m}$ spot size between 3 and $10 \mathrm{keV}$ at $10.7 \mathrm{~mm}$ focal distance accordingly to IfG Institute for Scientific Instrument, Berlin, Germany). The X-ray tube output can be filtered with different foils. The characteristics of the policapillary optics have been chosen in order to achieve the optimum output focal distance for safely analysis of valuable objects, without compromising the spatial resolution. A silicon drift detector (X123SDD, Amptek) with an active area of $25 \mathrm{~mm}^{2}$, a $500 \mu \mathrm{m}$ thick crystal and a resolution of about $127 \mathrm{eV}$ FWHM at $5.9 \mathrm{keV}$ Mn K-line completes the measuring head. Furthermore, an optical microscope (VZM 1000i, 2.5X-10X, Edmund Optics) coupled with a CCD camera (EO-0413 M color USB, $752 \times 480$ pixels, Edmund Optics) allows to inspect small areas while a HD camera provides a full view of the sample, both cameras are positioning at $45^{\circ}$ with respect to the beam. Finally two micro laser diodes (Micro Laser Diode Modules, $3 \mathrm{~mW}-635 \mathrm{~nm}$, Edmund Optics) are set on the measuring head in order to control the working distance (about $10 \mathrm{~mm}$ between the polycapillary lens exit and the sample). All the components of the spectrometer are mounted into a frame to create a tight fitting $90^{\circ} / 45^{\circ} \mathrm{XRF}$ excitation/detection geometry ensuring good stability. Fig. 1 shows the micro-XRF set-up and the details of the measuring head.

The analytical depth reached with the micro-XRF set-up obviously depends on the X-rays and the specific matrix under analysis, but for the gold artifacts studied it has been estimated to be less than $10 \mu \mathrm{m}$. Indeed, in the case of pure gold matrix, the attenuation length of $\mathrm{Cu} \mathrm{X}$ ray $\left(\mathrm{K}_{\alpha} 8.04 \mathrm{keV}\right)$, Au X-ray $\left(\mathrm{L}_{\alpha} 9.7 \mathrm{keV}\right)$ and $\mathrm{Ag} \mathrm{X}$-ray $\left(\mathrm{K}_{\alpha} 22.1 \mathrm{keV}\right)$ are
$2.5 \mu \mathrm{m}, 4.2 \mu \mathrm{m}$ and $8.8 \mu \mathrm{m}$, respectively. The X-ray tube was operated at $50 \mathrm{kV} / 0.6 \mathrm{~mA}$ and the acquisition time was $500 \mathrm{~s}$ for each point of analysis. A $1 \mathrm{~mm}$ thick aluminum filter was used (see Section 2.2). The acquired spectra were fitted using the WinQxas software (International Atomic Energy Agency, 2002).

\subsection{Analytical capabilities}

The use of a polycapillary lens in the excitation channel produces a significant change in the shape of the polychromatic excitation spectrum (Bichlmeier et al., 2001; MacDonald, 1996; Vittiglio et al., 2004). Specifically, the high energy of the polychromatic X-ray tube spectrum is filtered out. In addition, a $1 \mathrm{~mm}$ thick $\mathrm{Al}$ foil is placed at the exit of the X-ray tube, in order to filter the low energy component of the primary X-ray spectrum (acting as high-pass filter), improving the lateral resolution (Nakano et al., 2008; Tsuji et al., 2004). Indeed, $1 \mathrm{~mm} \mathrm{Al}$ foil can absorb $99 \%$ of X-rays between $1 \mathrm{keV}$ and $11 \mathrm{keV}$ while the $\mathrm{Rh}$ characteristic radiation is absorbed by $47 \%$. The lateral resolution provided by the polycapillary lens has been characterized scanning through a Cu grid (hole width of $113 \mu \mathrm{m}$ and bar width of $12 \mu \mathrm{m}$ ). Fig. 2 shows the effect of the $\mathrm{Al}$ foil on the beam spot size: the microbeam spot size decreases from $45 \mu \mathrm{m}$ (FWHM) to $30 \mu \mathrm{m}$ (FWHM) when the Al foil is used.

In order to estimate the effect of the polycapillary lens and the $\mathrm{Al}$ filter on the polychromatic spectrum in our set-up, a sample of certified composition, SRM-1412 multicomponent glass standard (medium-light matrix) from NIST, was analyzed. These measurements were performed with the polycapillary lens and then with a $1 \mathrm{~mm}$ diameter collimator in the same geometry and tube-to-sample distance, with and without the $\mathrm{Al}$ foil. Considering that the polycapillary lens provides a beam size of $30 \mu \mathrm{m}$, the results obtained with the collimator have been scaled to an equivalent aperture of $30 \mu \mathrm{m}$ diameter, assuming that the X-ray flux is homogeneous.

Fig. 3 represents the ratio between the net intensities of the detected peaks obtained with the polycapillary lens, $I_{p}$, and the intensities obtained using a $30 \mu \mathrm{m}$ equivalent diameter collimator, $I_{c}$, as a function of the X-ray energy. This mentioned ratio, also called gain factor, has been calculated for both configurations $\left(I_{p}\right.$ and $I_{c}$ ) using the Al foil (blue squares in Fig. 3) and without it (red dots in Fig. 3).

The transmission is improved up to 4000 times using a polycapillary lens compared to a collimator with the same spot size and in the same geometrical conditions. Indeed, in the configuration without the $\mathrm{Al}$ foil between 3 and $9 \mathrm{keV}$, the gain factor presents a maximum due to the better efficiency of the polycapillary optics for the transmission of low energy photons, due to the multiple reflections in the capillaries of the lens compared with the collimator (Gao and Ponomarev, 2003; Gao and Janssens, 2004; MacDonald, 2010). For the configuration with the $1 \mathrm{~mm} \mathrm{Al}$ foil (blue squares in Fig. 3) the increase of the gain factor for energies below $9 \mathrm{keV}$ is less evident because of the attenuation of the low energy photons in the filter, although the gain factor is still about 1000.

The polycapillary optics performance decreases as the photon energy increases. This decrease is the result of the reduced efficiency in the transmission of high energy photons, due to the energy dependence of the critical angle for total external reflection in the polycapillary lens (acting as a low-pass filter) (Gormley et al., 1999; MacDonald, 2010; Polese et al., 2014). This behavior is observed in Fig. 3 for both configurations (with and without the Al foil), where the gain factor for energies above $14 \mathrm{keV}$ presents a decrease (more than 50\%) and approaches values close to one for energies greater than $30 \mathrm{keV}$.

The same SRM 1412 glass from NIST and a bronze standard UE15 from the Centre Technique des Industrie de la Fonderie (CTIF) were used to measure the sensitivity and the limit of detection of the micro-XRF spectrometer. The analytical sensitivity $\left(S_{x}\right)$ and the limit of detection (LOD) were calculated using Eqs. (1) and (2) respectively found in (Alfeld et al., 2013; Janssens and Grieken, 2004) 

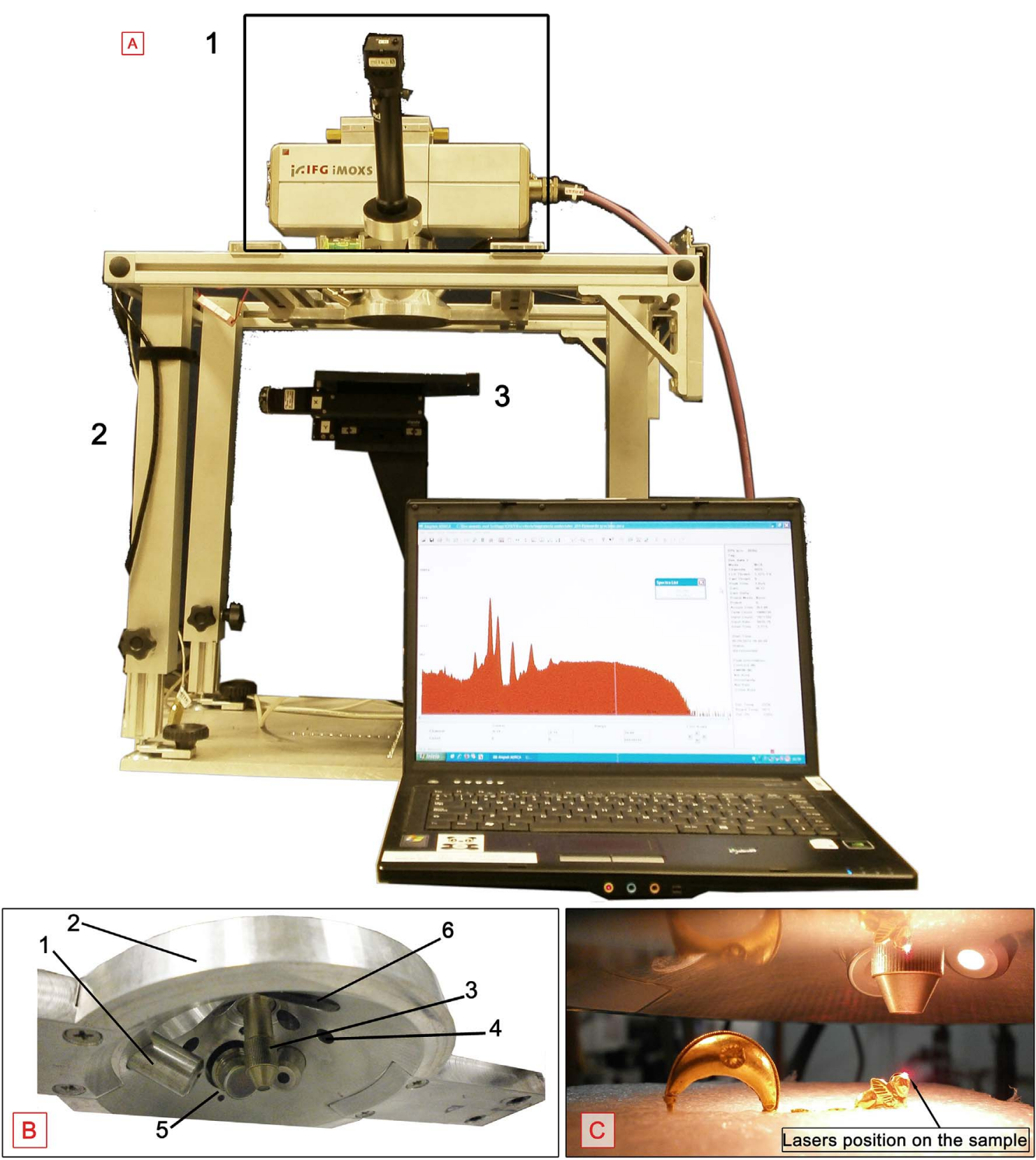

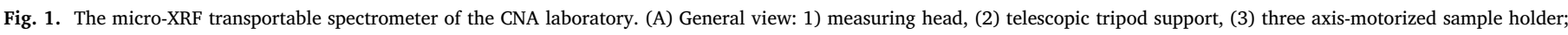

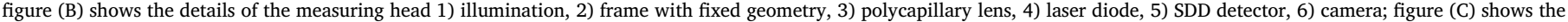
position of analysis point using lasers.

$S_{x}\left(E_{i}\right)=\frac{N_{x}\left(E_{i}\right) \cdot A}{t \cdot I \cdot C_{x}}$,

where $\mathrm{N}_{x}$ is the net peak area of $\mathrm{E}_{i}$ energy, $\mathrm{A}$ is a coefficient of absorption, $\mathrm{t}$ is the live time, $\mathrm{I}$ is the current intensity of the $\mathrm{X}$-ray tube and $\mathrm{C}_{x}$ is the concentration of the element $\mathrm{x}$ in the sample expressed in wt. $\%$.

$L O D_{i}=C_{i} \frac{k \sqrt{N_{b}}}{N_{x}\left(E_{i}\right)}$,

where $\mathrm{N}_{b}$ is the net background area below the peak and $\mathrm{k}$ is an integer constant depending on the significance level considered. In this case $\mathrm{k}$ $=3$ corresponds to a statistical confidence level of $99 \%$.

As it can be observed in Fig. 4, $\mathrm{K}_{\alpha}$ lines between $3.31 \mathrm{keV}\left(\mathrm{K}-\mathrm{K}_{\alpha}\right)$ and $26.27 \mathrm{keV}\left(\mathrm{Sb}-\mathrm{K}_{\alpha}\right.$ ) have sensitivity values between $10^{4}$ and $10^{7} \mathrm{cps}$ 、 $(m A \cdot w t . \%)$, reaching a maximum in the region between 7.5 and
$14.2 \mathrm{keV}\left(2.10^{6} \mathrm{cps} \backslash(\mathrm{mA} \cdot w t . \%)\right)$. The decrease of sensitivity from $23 \mathrm{keV}\left(\mathrm{K}_{\alpha}-\mathrm{Cd}\right)$ is due to the lower transmission at higher energies of the polycapillary optics (Alfeld et al., 2013; Vittiglio et al., 1999) (see Fig. 3) and the high level of bremsstrahlung background.

The limited K-line sensitivity for the elements lighter than potassium $(\mathrm{Z}=19)$ is mainly due to the absorption of the X-rays from the sample in the air but also to the absorption of the low energy component of the excitation spectrum by the $\mathrm{Al}$ filter.

The LOD value, reported in Table 1 , for the elements between Fe and $\mathrm{Sr}(6.4 \mathrm{keV}$ to $14.16 \mathrm{keV})$ is about $50 \mathrm{ppm}$ in both matrices, while for higher energies $(23.1<\mathrm{Z}>48 \mathrm{keV})$ the LOD is higher than $300 \mathrm{ppm}$. In addition, elements lighter than Ca present an increase of the LOD (more than 1000 ppm). LODs for these elements can be improved, if necessary, by removing the aluminum filter and/or using a $\mathrm{He}$ atmosphere. For example, the LOD of $\mathrm{K}$ without the $\mathrm{Al}$ filter is improved by a factor of 10 . 


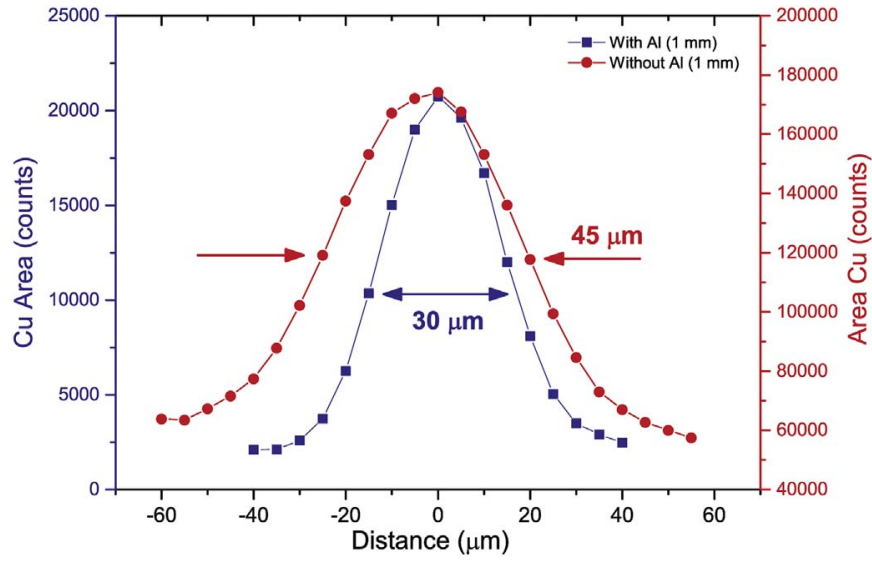

Fig. 2. Improvement of the lateral resolution using a filter. Linear scanning of a $12 \mu \mathrm{m} \mathrm{Cu}$ wire with (blue square) and without (red dots) $1 \mathrm{~mm} \mathrm{Al} \mathrm{foil.}$

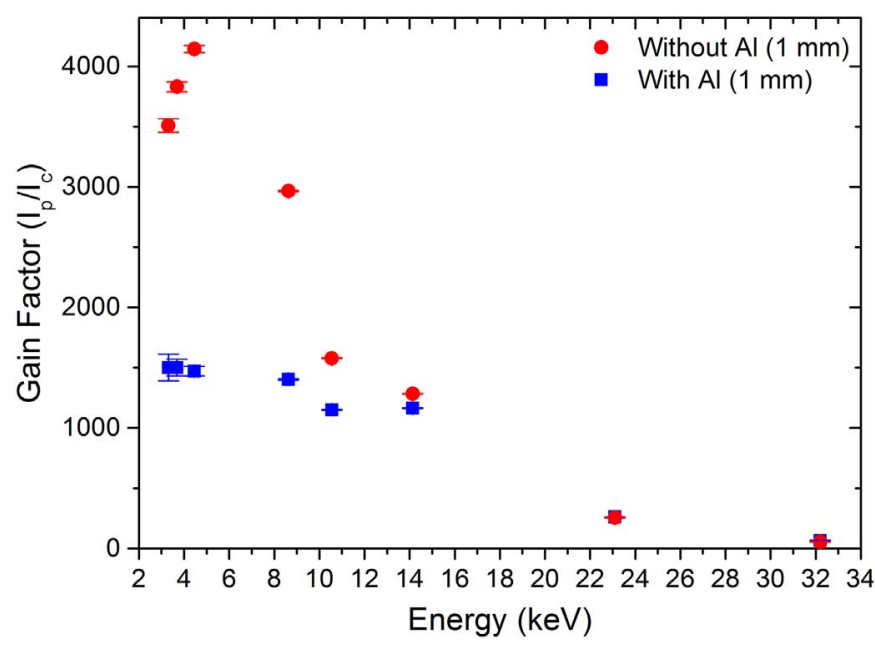

Fig. 3. Transmission of the polycapillary lens. Gain factor of the detected peaks of the multicomponent glass standard acquired with polycapillary optics (Ip) and the $30 \mu \mathrm{m}$ equivalent diameter collimator (Ic) as a function of the X-ray emission energy with and without $\mathrm{Al}$ foil.

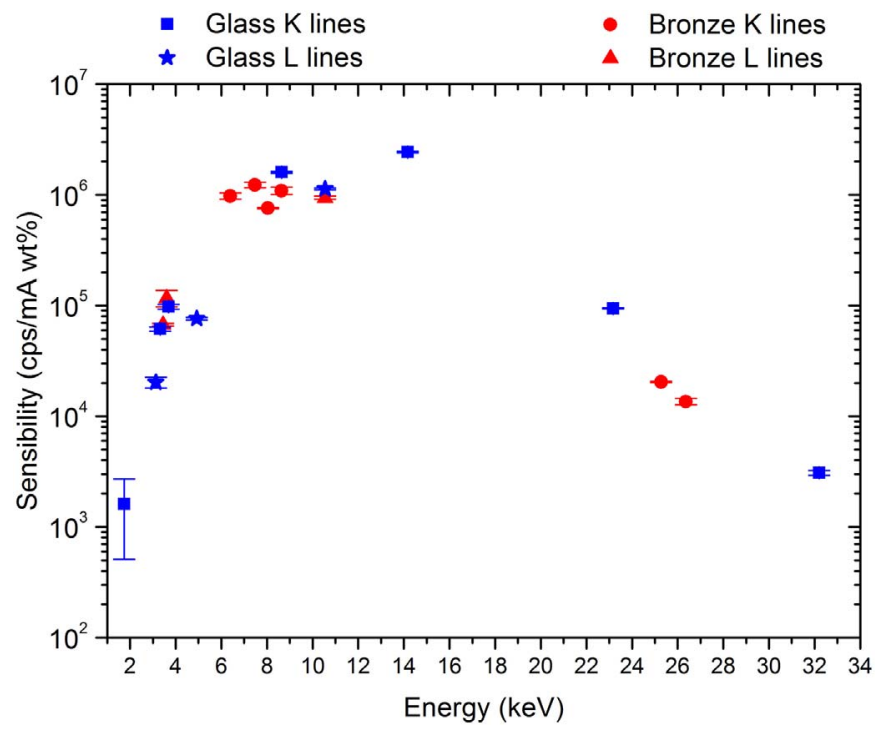

Fig. 4. $\mathrm{K}$ and $\mathrm{L}$ line sensitivity of the micro-XRF spectrometer. Measurement conditions: Al filter, polycapillary lens, $50 \mathrm{kV}, 0.6 \mathrm{~mA}, 500 \mathrm{~s}$ K and L line sensitivity of the SRM1412 glass standard (medium-light matrix) and the UE15 bronze standard (medium-heavy matrix).
Table 1

LOD values of the elements of the glass standard SRM 1412 and bronze standard UE15 in ppm. Measurement conditions: Al filter, polycapillary lens, $50 \mathrm{kV}, 0.6 \mathrm{~mA}, 500 \mathrm{~s}$.

\begin{tabular}{llll}
\hline Energy $(\mathrm{keV})$ & Elements & Glass SRM 1412 & Bronze UE15 \\
\hline 3.31 & $\mathrm{~K}\left(\mathrm{~K}_{\alpha}\right)$ & $1100 \pm 500$ & - \\
3.69 & $\mathrm{Ca}\left(\mathrm{K}_{\alpha}\right)$ & $800 \pm 400$ & - \\
6.39 & $\mathrm{Fe}\left(\mathrm{K}_{\alpha}\right)$ & - & $54 \pm 23$ \\
8.63 & $\mathrm{Zn}\left(\mathrm{K}_{\alpha}\right)$ & $25 \pm 13$ & $40 \pm 14$ \\
10.55 & $\mathrm{~Pb}\left(\mathrm{~L}_{\alpha}\right)$ & $30 \pm 10$ & $40 \pm 14$ \\
14.14 & $\mathrm{Sr}\left(\mathrm{K}_{\alpha}\right)$ & $30 \pm 15$ & - \\
23.11 & $\mathrm{Cd}\left(\mathrm{K}_{\alpha}\right)$ & $300 \pm 20$ & - \\
25.19 & $\mathrm{Sn}\left(\mathrm{K}_{\alpha}\right)$ & - & $460 \pm 130$ \\
26.27 & $\mathrm{Sb}\left(\mathrm{K}_{\alpha}\right)$ & - & $560 \pm 140$ \\
32.10 & $\mathrm{Ba}\left(\mathrm{K}_{\alpha}\right)$ & $2600 \pm 200$ & - \\
\hline
\end{tabular}

These results demonstrate that the instrument allows for the detection and quantification of major elements and even trace elements in gold jewels. The high lateral resolution of the micro-XRF device permits also to analyze very small details of an object. These characteristics, together with its portability, make the instrument a well suited device for the in-situ study and the characterization of cultural heritage materials.

\section{Application for the study of Etruscan gold jewels}

\subsection{Analyzed samples}

The majority of the Etruscan jewels and gold objects are related to the rich funerary artifacts found in coastal and interior cities of the Northwest of Italy. They reflect the proliferation of an aristocratic class, in particular from the seventh century B.C., which adopted the use of gold personal ornaments to underline their status symbol (Cristofani and Martelli, 1983; Perea, 1996). Based on the archaeological study of the stylistic characteristics of the objects and the socio-economic changes, four periods can be distinguished in the goldsmith Etruscan production: Villanovian period (IX-early VIII century B.C.), Orientalizing period (second half of VIII-VII century B.C.), Archaic period (VI-early V century B.C.) and Classic and Hellenistic period (V-III century B.C.) (Cristofani and Martelli, 1983).

A set of 15 gold jewels (14 archaeological objects +1 forged) dating back to the Etruscan Orientalizing period (VII century B.C.) was analyzed in-situ using the micro-XRF transportable spectrometer in the framework of an extensive measurement campaign at the National Archaeological Museum of Florence (Italy) in collaboration with the LABEC Laboratory of Florence. The objects were selected in order to represent the Etruscan production in terms of decoration (thin sheet, repoussé, granulation and filigree) and manufacturing techniques (lost wax and multiple soldering points) (Nestler and Formigli, 1994).

As previously stated, three joining techniques were the most used in antiquity. Compositional analysis could be of great help in identifying the soldering methods, since the variations in the concentration of $\mathrm{Au}$, $\mathrm{Ag}$ and $\mathrm{Cu}$ in the soldering area with respect to that in the joined parts can be used as markers of the joining technique. Indeed, when brazing was used, the joining areas show an increase in $\mathrm{Ag}$ and $\mathrm{Cu}$ contents; the solid state diffusion bonding is characterized by an increase of $\mathrm{Cu}$ content in the soldering area and fusion welding is identified by an increase of Au content (Demortier, 1996; Scrivano et al., 2013). However, a fourth method has been cataloged recently: autogenous welding, that does not show compositional changes and is only detectable by visual inspection (Ferro et al., 2008; Scrivano et al., 2013, 2017).

The objects analyzed (Fig. 5) present a good state of conservation, all of them coming from excavations of archaeological contexts of three different ancient Etruscan colonies: Vetulonia, Populonia and Bisenzio.

In order to simplify the presentation of the results, the items have been divided into four groups. These groups, summarized in Table 2, are based on the type of decoration and production techniques used: 

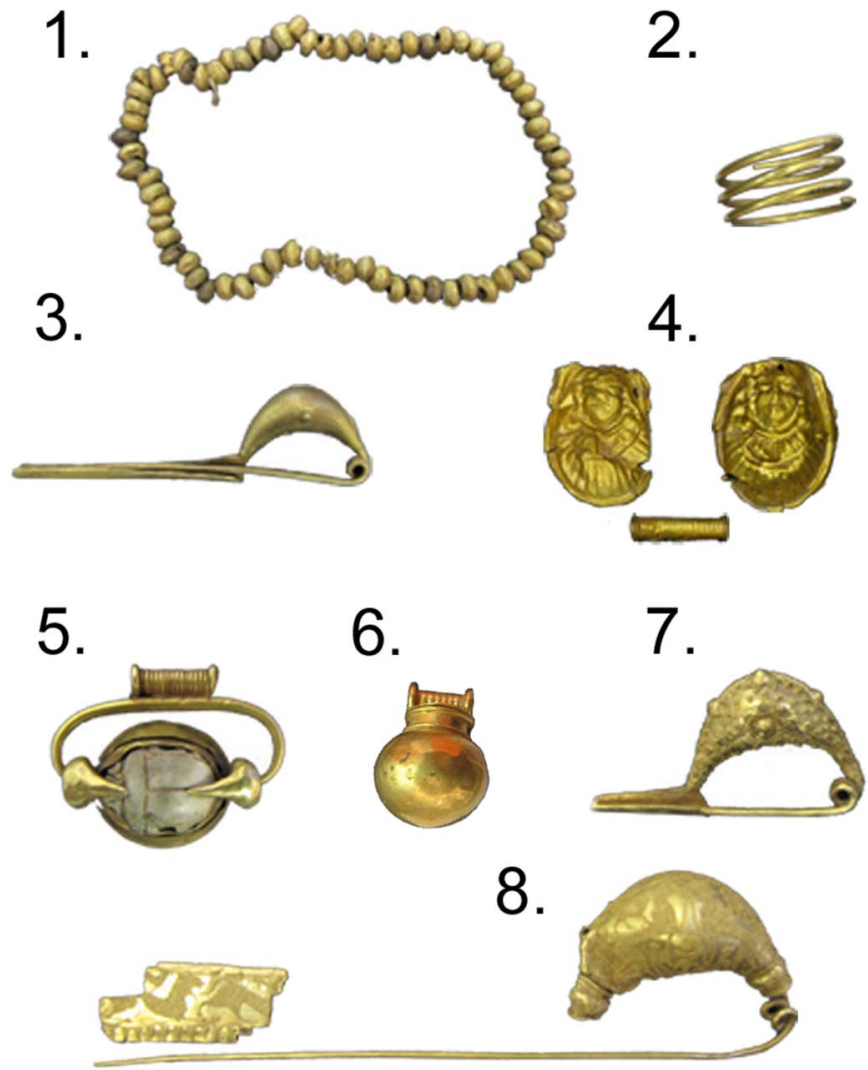

Fig. 5. The Etruscan jewel collection of the National Archaeological Museum of Florence analyzed by the transportable micro-XRF spectrometer. 1) Necklace 75130, 2) one of the two spirals 80293, 3) Fibula 78282, 4) two pendants and one of the two holding elements SNI cass. 33; 5) one of the three scarab pendants 85585,6 ) one of the two pendants 116600 and 116601, 7) Fibula 73596, 8) Fibula 75517.

Table 2

Group classification of Etruscan jewels of National Archaeological Museum of Florence (Italy), analyzed by non-destructive micro-XRF technique.

\begin{tabular}{llll}
\hline $\begin{array}{l}\text { Museum } \\
\text { reference }\end{array}$ & Archaeological context & Groups & Fig. 5 \\
\hline 75130 & Vetulonia & G1 Objects without joints & 1 \\
80292 & & & 2 \\
80293 & Vetulonia & G2 Simple objects with & 2 \\
78282 & & joints & 3 \\
SIN cass 33 & & & 4 \\
$(2+2)$ & Bisenzio & & 5 \\
$85585(3)$ & Populonia & & 6 \\
116600 & Vetulonia & G4 objects with filigree and & 7 \\
116601 & & granulation & 6 \\
73596 & Vetulonia & G3 objects with granulation & 8 \\
75517 & & & \\
\hline
\end{tabular}

G1, objects without joints; G2 simple objects with joints; G3 objects with granulation and G4 objects with filigree and granulation.

The objects were analyzed using the micro-XRF spectrometer in order to characterize the alloy composition of sheets, threads, filigrees, granules, as well as the joining zones that are usually smaller than 100 $\mu \mathrm{m}$. The information obtained was used to characterize the manufacture technique employed for their production.

\subsection{Results and discussion}

For the quantitative analysis of the XRF spectra, the elemental sensitivity method was used (Tylecote, 1992). Three different standards with compositions similar to those of the archaeological samples were
Table 3

Micro-XRF results for a gold standard not used for the sensitivity calibration curve. The mean value is calculated for 10 non-consecutive measurement, in parenthesis St. Dev considering $3 \sigma$.

\begin{tabular}{|c|c|c|c|}
\hline & Au59 & & \\
\hline & $\mathrm{Au}$ & $\mathrm{Ag}$ & $\mathrm{Cu}$ \\
\hline Standard & 29.74 & 58.11 & 12.19 \\
\hline Measured & 29.4 & 59.1 & 11.45 \\
\hline Mean value & $29.55(0.25)$ & $58.98(0.21)$ & $11.7(0.1)$ \\
\hline
\end{tabular}

employed to obtain the sensitivity curve (Standard G1: 95.98\% Au, 1.99\% Ag, 2.02\% Cu; Standard G2: $90.01 \% \mathrm{Au}, 7.95 \% \mathrm{Ag}, 2.04 \% \mathrm{Cu}$; Standard G3: $75 \% \mathrm{Au}, 15 \% \mathrm{Ag}, 10 \% \mathrm{Cu}$ ). The results are expressed in terms of weight percent (wt. \%), normalized to $100 \mathrm{wt}$. \%. In Table 3 are reported the results obtained for the gold standard Au59, not used for obtaining the sensitivity calibration curve. The relative uncertainties of the concentrations, obtained from WinQxas (International Atomic Energy Agency, 2002) were 3\% for $\mathrm{Au}, 3 \%$ for $\mathrm{Ag}$ and $11 \%$ for $\mathrm{Cu}$.

The 15 selected Etruscan jewels were analyzed in many different points (at least 20 points per object) in order to characterize both the alloy and the manufacture method employed. The quantitative analysis of the objects, excluding joining zones, reveals that a very homogenous alloy was used for the production of each jewel, for this reason in Fig. 6 the average values are presented. Trace elements from the burial have been also detected but they were not taken into account in this study. The alloys employed in the manufacture of all the samples are characterized by a low copper content, close to $2.5 \mathrm{wt}$. \%. Such amount of $\mathrm{Cu}$ is generally related to gold and silver ores as impurities (Guerra, 2008; Oddy, 1980; Ramage and Craddock, 2000; Tylecote, 1992), suggesting a natural provenance of this element in the alloy. On the contrary, silver and gold content varies significantly among the different samples, presenting mainly high values of silver, in particular for the objects from Vetulonia, where the concentration of $\mathrm{Ag}$ is always higher than $20 \%$.

With respect to the production processes employed by the Etruscan goldsmiths, objects belonging to the 4 groups will now be described. Group 1 does not present any kind of welding/soldering technique. The manufacture technique is simpler than for the other objects and it seems to be related to the production techniques typical of the Bronze Age (Perea, 1996). In fact, the beads of the necklace (n. 75130) present a homogenous composition of $71 \% \mathrm{Au}, 27 \% \mathrm{Ag}$ and $2 \% \mathrm{Cu}$ and considering their spherical shape without joining zone, it can be assumed

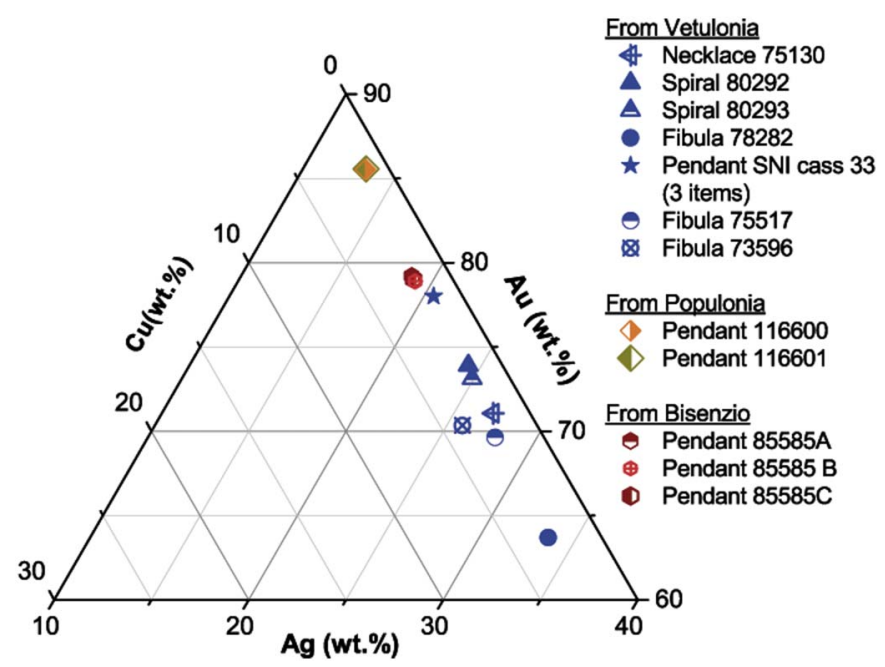

Fig. 6. Alloy composition of the Etruscan jewels. Due to the homogeneity of each objects, the average values, normalized to $100 \%$, are presented. The maximum standard deviation for the average values are $1 \%$ for $\mathrm{Au}$ and $\mathrm{Ag}$ and $2 \%$ to $5 \%$ for $\mathrm{Cu}$. 


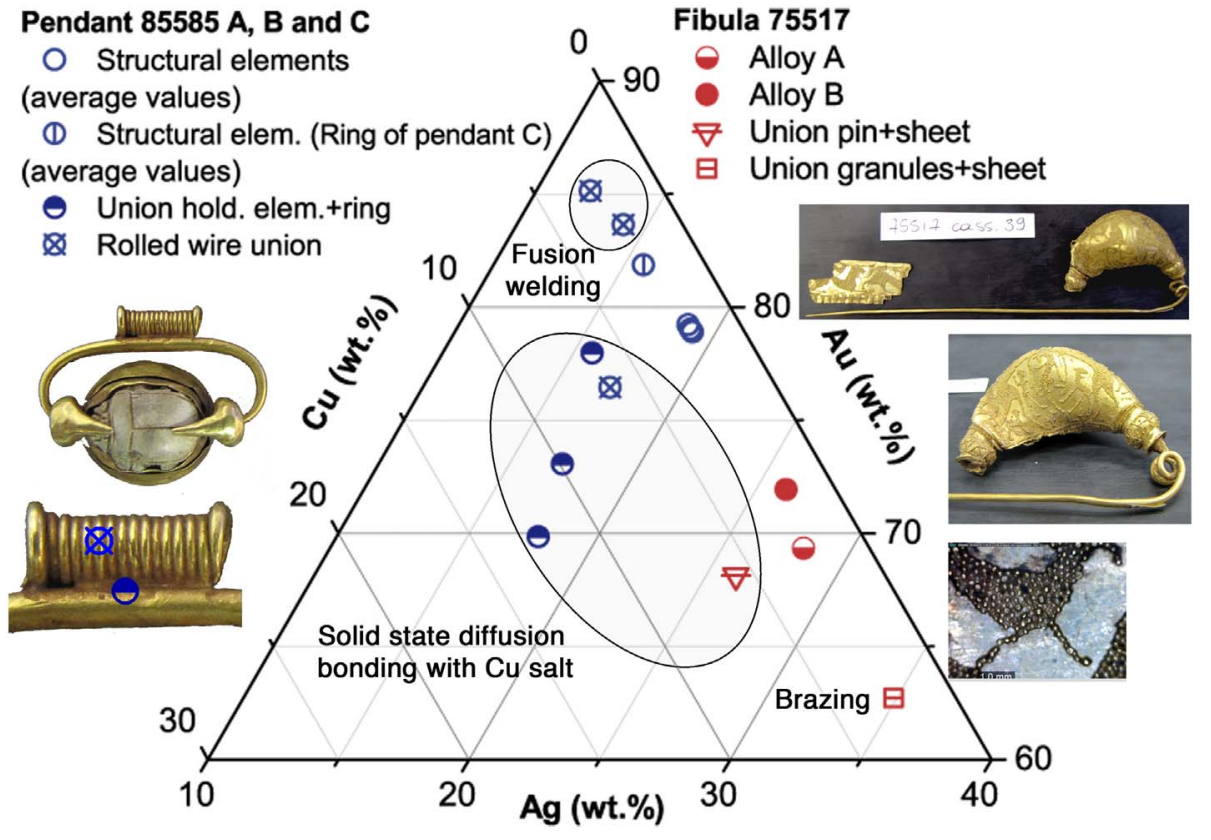

Fig. 7. Micro-XRF analysis of the pendants n. 85585 A, B and $\mathrm{C}$ and of the Fibula n. 75517. $\mathrm{Au}, \mathrm{Ag}$ and $\mathrm{Cu}$ average concentrations of the structural elements of the objects are represented by hollow circles. Some relevant joining zones are also shown. that they were produced using the lost wax technique. On the other hand, the two spirals for the hair (n. 80292 and 80292) are constituted by a single massive wire without welding or soldering points, probably produced from a hammered foil with a composition of $74 \% \mathrm{Au}, 24 \% \mathrm{Ag}$ and $2 \% \mathrm{Cu}$. The composition of the spirals is very similar, thus it is possible to assume that they have been manufactured using the same technique and probably in the same workshop.

Except for Group 1, all of the other jewels present several joining points. The most important common characteristic that identifies these objects is the wide use of the solid state diffusion bonding method, which is a method largely used by Etruscan goldsmiths (Ramage and Craddock, 2000). In particular, the majority of the objects belonging to Group 2 (n. 116600, 116601, 78282, two holding elements of SNI cass 33), all items without decoration of filigree or granulation, seem to have been manufactured only using this method, where $\mathrm{Cu}$ diffusion creates a local binary alloy (Au-Cu) with a melting point about $890^{\circ} \mathrm{C}$ (Demortier, 1996; Mathot and Demortier, 2004).

The three scarab pendants (n. 85585 A, B and C) of Group 2 represent an exception. These objects exhibit the same style and very similar composition as it is shown in Fig. 7. The average values are presented in the graph for simplicity and only one point of each type of join is shown, although many points of analysis support the type of soldering method. The pendants present a common structure consisting of two parts: a cylindrical holding element formed by a spiral rolled wire joined to a supporting ring. The analysis of these objects reveals the use of several joining methods in this collection. Fusion welding is present in samples $\mathrm{A}$ and $\mathrm{C}$ in the spiral wire to produce the holding element, while solid state diffusion bonding with $\mathrm{Cu}$ salts is detected in pendant B (Fig. 7). However, the latter method was also detected in the union between the holding elements and the rings. These results support the hypothesis of the use of different manufacture processes by the intervention of various craftsmen to produce the holding element or even the recycling of imported pieces.

A similar shape of the holding element has been found in other objects, such as the three pendants SNI cass 33, n. 116600 and 116601. Nonetheless, the compositional analysis of these jewels shows a different method of manufacture. In these cases, the holding elements are made out of a carved sheet simulating the rolled wire without joining zone in the sheet, while the lateral ring is joined by solid state diffusion bonding method instead of fusion welding (copper increases from 0.96 wt. $\%$ in the components to 1.80 wt.\% in the join zone).
Interesting information can be deduced from the study of the manufacture processes employed in the more complex objects belonging to Group 3 and Group 4. In order to produce these items, goldsmiths employed small embossing elements, granules and/or filigrees and different soldering methods, as for example in fibulae n. 75517 and n. 73596. In these cases, an alloy with a lower melting point was employed to join granules and filigree to their supporting sheets. The analysis of these objects has shown a silver increase of $24 \%$ in the soldering points between granules and sheet for the fibula $\mathrm{n}$. 75517 (Fig. 7) and an increment of $12 \%$ and $16 \%$ in the soldering points between granules and sheet and between filigree and sheet for the fibula n. 73596, respectively. Thus, this analysis shows how the Etruscan granules are also joined by brazing method and not only by solid state diffusion bonding as was traditionally believed (Cristofani and Martelli, 1983; Ferro et al., 2008; Mello et al., 1983; Parrini et al., 1982).

The micro-XRF analysis can reveal not only information about the joining methods employed but also about the different stages of the production process. That is the case of sample $\mathrm{n}$. 75517, where besides the soldering methods employed (solid state diffusion bonding for the join of the pin and brazing for the granules, as said before) the analysis reveals that two different alloys were employed for the manufacture of this jewel, as shown in the ternary graph in Fig. 7. An alloy, with a concentration of $69 \% \mathrm{Au}, 28 \% \mathrm{Ag}$ and $2.5 \% \mathrm{Cu}$, named alloy $\mathrm{A}$, was used to produce the structural sheet and the granules used to decorate the catch plate of the fibula, while a second alloy richer in gold, named $\mathrm{B}(72 \% \mathrm{Au}, 26 \% \mathrm{Ag}$ and $1.8 \% \mathrm{Cu})$ was employed for the manufacture of the pin and the granules decorating the "sanguisuga". These two alloys suggest that the object was made in two consecutive steps: in the first one the alloy A was used to fabricate the structure and the granules of the catch plate and secondly the alloy B was used to produce the granules that decorate the "sanguisuga" and the pin.

Additionally to the above-mentioned objects, during the measurement campaign, we had the possibility to analyze the sample with reference n. 85037. This jewel was acquired by the National Archaeological Museum of Florence in 1911 as a fibula from Populonia dating back to VII century B.C., similar to sample n. 75517 previously presented. However, the careful historical and artistic analysis revealed later that the object was a forgery. The micro-XRF analysis of this object will be presented in order to illustrate how the analysis and knowledge of ancient manufacture techniques can contribute positively to the 


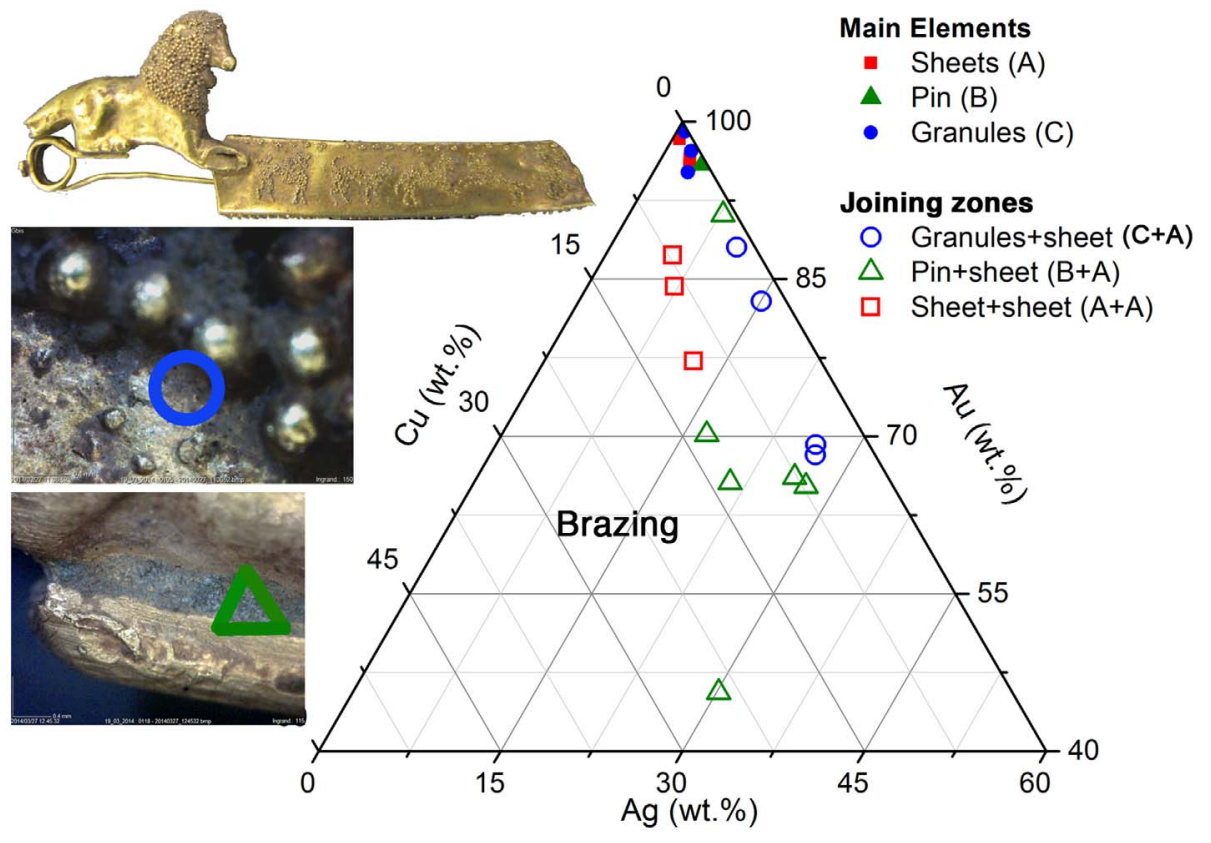

Fig. 8. Micro-XRF analysis of sample n. 85037. Au, Ag, and $\mathrm{Cu}$ concentration of the main elements and their joining zones. The relative uncertainties for the main elements are Au 3\%, Ag 25\% and $\mathrm{Cu} 15 \%$, while for the soldering zones are $\mathrm{Au} 3 \%, \mathrm{Ag} 3 \%$ and $\mathrm{Cu} 11 \%$. authentication of ancient jewelry.

Fig. 8 shows the results of the forged fibula. The main elements of the fibula present an alloy very rich in gold (filled squares, triangles and circles) in many cases reaching concentrations of gold of about $99 \%$, with silver and copper concentrations lower than $1 \%$ without the presence of the typical elements related to burial conditions ( $\mathrm{Ca}, \mathrm{Ti}, \mathrm{Mn}$, $\mathrm{Fe}, . .$.$) . An alloy with such a content of gold is practically impossible to$ achieve without an adequate refining process which removes the impurities in the metal (mostly $\mathrm{Ag}$ and $\mathrm{Cu}$ ). The refining procedures were employed from the appearance of monetization processes in Roman times (Oddy, 1980; Ramage and Craddock, 2000). This result suggests that the metallurgical method used for the production of this object does not correspond to the majority of the traditional methods used by the Etruscan (Bobin and Guegan, 2009).

Moreover, the analysis of the joining zones shows a considerable increase in silver and copper composition (reaching 30\% Ag and 20\% $\mathrm{Cu}$ in the zone between the sheet and the pin), demonstrating the use of a brazing alloy in the analyzed joining zones (Fig. 8). This solder alloy has a melting point about $900^{\circ} \mathrm{C}$, i.e. $150^{\circ} \mathrm{C}$ lower than the melting point of the starting alloy used for the production of the jewel (the fusion temperature of pure gold is $1064^{\circ} \mathrm{C}$ ) (Scott, 1991). In authentic jewels studied previously, the compositional changes in the soldering zones are usually about 1 to $5 \%$ compared to the alloys of the elements to be joined.

Although this fibula was analyzed by other authors (Rastrelli et al., 2009) using XRF and LIBS, they could not reach conclusive results. The dimension of the spot size prevented the correct analysis of the joining zones and even, in some cases it was impossible to distinguish between joining areas and structural elements of the fibula.

\section{Conclusions}

The transportable micro-XRF system from the CNA laboratory allows in-situ analysis with a reduced beam size by means of polycapillary optics. The characterization of this set-up has demonstrated that using an $\mathrm{Al}$ filter in front of the polycapillary lens, the lateral resolution is improved by $30 \%$. The measurement of the excitation spectra shows that by using focusing optics, it is possible to increase the flux intensity up to four orders of magnitude with respect to the use of a collimator. The sensitivity and the detection limits of the system enable the quantification of major, minor and trace elements present in the sample. The micro-XRF device is a powerful tool in the study of metallic objects, in particular of jewelry with complex decoration. The transportability is a characteristic of this system allowing in-situ study of cultural heritage objects which cannot be moved to the laboratory. In the case of the study of gold Etruscan jewels, the analyses of the alloys have shown a copper concentration about $2.5 \%$ and a great variability of silver and gold in this group of Etruscan jewels. In regard to the soldering methods, three kinds of joining methods have been found, the most common being the copper diffusion bonding. The decorative techniques range from the simple decoration, such as stamp sheet or lost wax, to complex decorative patterns, using different decoration elements in the same object (filigree, granulation, repoussé), in order to produce an extremely complex jewel despite its reduced size. The analysis of the forged fibula has shown a clear example of how a micro beam can be indispensable in the study of ancient jewelry, taking full advantage from the analysis, and for the precise characterization of the production techniques; both aspects can contribute to the recognition of forged or dubious objects. These results show the suitability and strength of the micro-XRF analysis applied to cultural heritage materials providing valuable information in order to describe the manufacture technique and the production process employed by the Etruscan goldsmiths.

\section{Acknowledgments}

The authors wish to thank Dr. Giuseppina Carlotta Cianferoni, Director of the Archaeological Museum of Florence, for her invaluable support and help. The authors wish to thank the research group of LABEC laboratory for the support spent during the measurements. The authors also wish to thank Prof. Emilio Gómez for his contribution in the development of the illumination system of the spectrometer. This work has been partially supported by the project HAR200907449 of the Spanish Ministry of Science and Innovation. S. Scrivano acknowledges the financial support from the V Plan Propio de Investigación of the University of Seville. 


\section{Appendix A}

Table A1

Average value of the alloy composition of the 14 analyzed Etruscan jewels.

\begin{tabular}{|c|c|c|c|c|c|c|c|}
\hline Sample & N Tot & Au wt.\% & St. dev & Ag wt.\% & St. dev. & $\mathrm{Cu}$ wt.\% & St. dev. \\
\hline 75130 & 21 & 71.1 & 0.9 & 27.0 & 1.1 & 1.9 & 0.3 \\
\hline 80292 & 7 & 73.9 & 0.9 & 24.3 & 0.8 & 1.8 & 0.5 \\
\hline 78282 & 10 & 63.7 & 0.4 & 33.5 & 0.3 & 2.74 & 0.21 \\
\hline SIN cass. 33 & 25 & 78.0 & 0.8 & 20.5 & 0.9 & 1.5 & 0.9 \\
\hline 75517 & 53 & 69.6 & 2.1 & 27.8 & 1.8 & 2.5 & 0.7 \\
\hline 116601 & 22 & 85.6 & 0.5 & 13.25 & 0.45 & 1.2 & 0.5 \\
\hline $85585 \mathrm{~A}$ & 16 & 79.2 & 0.5 & 18.7 & 0.4 & 2.01 & 0.19 \\
\hline $85585 B$ & 13 & 78.9 & 0.5 & 19.1 & 0.6 & 2.0 & 0.2 \\
\hline 85585C & 8 & 79.0 & 0.6 & 19.0 & 0.5 & 2.01 & 0.19 \\
\hline
\end{tabular}

Table A2

Summary table of the alloy and soldering zone composition of the samples $85585 \mathrm{~A}, \mathrm{~B}, \mathrm{C}$ and 75517.

\begin{tabular}{|c|c|c|c|}
\hline Zone of analysis & Au wt. $\%$ & Ag wt. $\%$ & Cu wt. $\%$ \\
\hline \multicolumn{4}{|l|}{ Pendants $85585 A, B$ and $C$} \\
\hline Structural elements of Pendant A (average value) & 79 & 19 & 2.0 \\
\hline Structural elements of Pendant B (average value) & 79 & 19 & 2.0 \\
\hline Structural elements of Pendant C (average value) & 79 & 19 & 2.0 \\
\hline Ring of pendant $C$ (average values) & 82 & 15.7 & 2.4 \\
\hline Union hold. elem. + ring & 70 & 18 & 12.4 \\
\hline Union hold. elem. + ring & 78 & 15.7 & 6.3 \\
\hline Union hold. elem. + ring & 73 & 17 & 9.9 \\
\hline Rolled wire union & 85 & 12.1 & 2.8 \\
\hline Rolled wire union & 84 & 14.1 & 2.3 \\
\hline Rolled wire union & 76 & 17 & 6.4 \\
\hline \multicolumn{4}{|l|}{ Fibula 75517} \\
\hline Alloy B (average value) & 72 & 26 & 1.9 \\
\hline Alloy A (average value) & 69 & 28 & 2.5 \\
\hline Union pin + sheet & 68 & 26 & 5.7 \\
\hline Union granules + sheet & 63 & 35 & 2.4 \\
\hline
\end{tabular}

Table A3

Summary table of the alloy and soldering zone composition of the sample 85037 .

\begin{tabular}{|c|c|c|c|}
\hline Zone of analysis & Au wt. $\%$ & Ag wt. $\%$ & Cu wt. $\%$ \\
\hline Sheet & 99 & 0.2 & 0.2 \\
\hline Sheet & 99 & 0.4 & 0.3 \\
\hline Sheet & 99 & 0.3 & 0.2 \\
\hline Sheet & 99 & 0.4 & 0.3 \\
\hline Sheet & 100 & 0.3 & 0.2 \\
\hline Sheet & 96 & 2.4 & 1.2 \\
\hline Sheet & 98 & 0.6 & 1.1 \\
\hline Sheet & 99 & 0.4 & 0.3 \\
\hline Sheet & 99 & 0.3 & 0.2 \\
\hline Sheet & 96 & 2.7 & 1.5 \\
\hline Pin & 96 & 3.6 & 0.4 \\
\hline Pin & 100 & 0.3 & 0.2 \\
\hline Pin & 100 & 0.2 & 0.2 \\
\hline Granules & 95 & 2.9 & 2.0 \\
\hline Granules & 99 & 0.7 & 0.3 \\
\hline Granules & 97 & 2.1 & 0.7 \\
\hline
\end{tabular}




$\begin{array}{ll}\text { Union granules }+ \text { sheet } & 88 \\ \text { Union granules }+ \text { sheet } & 68 \\ \text { Union granules }+ \text { sheet } & 83 \\ \text { Union granules }+ \text { sheet } & 69 \\ \text { Union pin }+ \text { sheet } & 91 \\ \text { Union pin }+ \text { sheet } & 66 \\ \text { Union pin }+ \text { sheet } & 65 \\ \text { Union pin }+ \text { sheet } & 46 \\ \text { Union pin }+ \text { sheet } & 70 \\ \text { Union pin }+ \text { sheet } & 66 \\ \text { Union sheet }+ \text { sheet } & 87 \\ \text { Union sheet }+ \text { sheet } & 77 \\ \text { Union sheet }+ \text { sheet } & 84\end{array}$

10.5

27

15.1

26

7.8

26

28

30

16.9

21.1

5.6

12.3

7.2
1.5

4.9

2.1

4.4

1.1

7.7

7.2

24

12.9

13.3

7.2

10.5

\section{References}

Alfeld, M., Pedroso, J.V., Van Eikema Hommes, M., Van der Snickt, G., Tauber, G., Blaas, J., Haschke, M., Erler, K., Dik, J., Janssens, K., 2013. A mobile instrument for in situ scanning macro-XRF investigation of historical paintings. J. Anal. At. Spectrom. 28, 760-767. http://dx.doi.org/10.1039/C3JA30341A.

Baldini Lippolis, I., Guaitoli, M.T., 2009. Oreficeria antica e medievale. Tecniche, produzione, societa. Ornamenta 1, 71-78.

Bichlmeier, S., Janssens, K., Heckel, J., Gibson, D., Hoffmann, P., Ortner, H.M., 2001. Component selection for a compact micro-XRF spectrometer. X-Ray Spectrom. 30, $8-14$.

Bobin, O., Guegan, H., 2009. A new approach to the authentication of goldwork using combined scanning electron microscopy and external-beam PIXE. ArcheoSciences, revue d'archeometrie $33,341-347$.

Cristofani, M., Martelli, M., 1983. L'oro degli etruschi. De Agostini, Ist. Geografico.

Demortier, G., 1996. Ion beam studies of archaeological gold jewellery items. Nucl. Inst. Meth. B 113, 347-353.

Echt, R., Thiele, W.R., 1993. Sintering, Welding, Brazing and soldering as bonding techniques in Etruscan and Celtic goldsmithing. In: Prehistoric, Gold in Europe. Mines, Metallurgy and Manufacture. Proceeding of the NATO Advanced Research Workshop. Kluwer Academic Publishers.

Ferro, D., Formigli, E., Pacini, A., Tossini, D., 2008. La saldatura nell'oreficeria antica. Centro Nazionale delle Ricerche (CNR).

Ferro, D., Virgili, V., Carraro, A., Formigli, E., Costantini, L., 2009. A multi-analytical approach for the identification of technological processes in ancient jewellery. ArcheoSciences, revue d'archeometrie 33, 351-357.

Gao, N., Ponomarev, I.Y., 2003. Polycapillary X-ray optics: manufacturing status, characterization and the future of the technology. X-Ray Spectrom. 32, 186-194. http:// dx.doi.org/10.1002/xrs.599.

Gao, N., Janssens, K., 2004. Polycapillary X-Ray Optics. In: X-Ray Spectrometry. John Wiley and Sons Ltd..

Gormley, J., Jach, T., Steel, E., Xiao, Q.F., 1999. Polycapillary X-ray optic, spectral gain and transmission. X-Ray Spectrom. 28, 115-120.

Guerra, M.F., 2008. Etruscan gold jewellery: genuine, restored or pastiche? In: Acta VII Congreso Ibérico de Arqueometría.

Guerra, M.F., Tissot, I., 2013. The role of nuclear microprobes in the study of technology, provenance and corrosion of cultural heritage: the case of gold and silver items. Nucl. Inst. Meth. B 306, 227-231.

International Atomic Energy Agency, 2002. WinQXAS - Quantitative X-Ray Analysis System for MS Windows operating system. (version 1.40).

Janssens, K., Van Grieken, R., 2004. Non-Destructive Microanalysis of Cultural Heritage Materials. In: Comprehensive Analytical Chemistry. vol. VLII Elsevier B.V..

Karydas, A.G., Kotzamani, D., Bernard, R., Barrandon, J.N., Zarkadas, Ch, 2004. A compositional study of a museum jewellery collection (7th-1st BC) by means of a portable XRF spectrometer. Nucl. Inst. Meth. B 226, 15-28.

MacDonald, C.A., 1996. Application and measurements of polycapillary X-ray optics. J. Xray Sci. Technol. 6, 32-47. http://dx.doi.org/10.3233/XST-1996-6102.

MacDonald, C.A., 2010. Focusing polycapillary optics and their applications. X-Ray Opt. Instrum. 1-17 (Article ID 867049).

Mathot, S., Demortier, G., 2004. Diffusion bonding from antiquity to present times. Nucl.
Inst. Meth. B 226, 222-230.

Mello, E., Parrini, P., Formigli, E., 1983. Welding techniques of two bracelets from Vetulonia. Am. J. Archaeol. 87, 548-551.

Nakano, K., Matsuda, A., Nodera, Y., Tsuji, K., 2008. Improvement of spatial resolution of micro-XRF by using a thin metal filter. X-Ray Spectrom. 37, 642-645.

Nestler, G., Formigli, E., 1994. Granulazione Etrusca. Un'Antica arte orafa. Nuova Immagine.

Oddy, W.A., 1980. Aspects of Early Metallurgy. vol. 17 British Museum.

Papadopoulou, D., Zachariadis, G., Anthemidis, A., Tsirliganis, N., Stratis, J., 2006. Development and optimisation of a portable micro-XRF method for in situ multielement analysis of ancient ceramics. Talanta 68 (5), 1692-1699.

Parrini, P., Formigli, E., Mello, E., 1982. Analysis of orientalizing jewelry from Marsigliana d'Albegna. Am. J. Archaeol. 86, 118-121.

Perea, A., 1996. Historia del oro en el Museo Arquelógico Nacional, Vol. 3, Ministero de Educación y Cultura.

Polese, C., Dabagov, S.B., Esposito, A., Hampai, D., Gorghinian, A., Liedl, A., Ferretti, M., 2014. Experimental study for the feasibility of using hard X-rays for micro-XRF analysis of multilayered metals. AIP Adv. 4, 077128.

Potts, P.J., 2008. Portable X-ray Fluorescence Spectrometry: Capabilities for In Situ Analysis. Editorial Royal Society of Chemistry, Cambridge, UK.

Ramage, A., Craddock, P., 2000. King Croesus' Gold: Excavations at Sardis and the History of Gold Refining. Harvard University Art Museums, in association with the British Museum Press, pp. 272.

Rastrelli, A., Miccio, M., Troalen, L., Martinón-Torres, M., Guerra, M.F., Siano, S., Sumbrera, A., Vitobello, M.L., 2009. Modern and ancient gold jewellery attributed to the Etruscans: a science-based study. ArcheoSciences, revue d'archeometrie 33, 357-364.

Scott, D.A., 1991. Metallography and Microstructure of Ancient and Historic Metals. The Getty Conservation Institute, pp. 84

Scrivano, S., Gómez-Tubío, B., Ortega-Feliu, I., Ager, F.J., Moreno-Suárez, A.I., Respaldiza, M.A., de la Bandera, M.L., Marmolejo, A., 2013. Identification of soldering and welding processes in ancient gold jewelry. X-Ray Spectrom. 42, 251-255.

Scrivano, S., Gómez-Tubío, B., Ortega-Feliu, I., Ager, F.J., Paul, A., Respaldiza, M.A., 2017. Compositional and microstructural study of joining methods in archaeological gold objects. X-Ray Spectrom. 46, 123-130.

Tissot, I., Tissot, M., Manso, M., Alves, L.C., Barreiros, M.A., Marcelo, T., Carvalho, M.L., Corregidor, V., Guerra, M.F., 2013. The earrings of Pancas treasure: analytical study by X-ray based techniques - a first approach. Nucl. Inst. Meth. B 306, 236-240.

Tsuji, K., Injuk, J., Van Grieken, R., 2004. X-Ray Spectrometry: Recent Technological Advances. John Wiley and Sons, Ltd.

Tylecote, R.F., 1992. A History of Metallurgy, second ed. Maney for The Institute of Materials.

Vittiglio, G., Bichlmeier, S., Klinger, P., Heckel, J., Fuzhong, W., Vincze, L., Janssens, K., Engström, P., Rindby, A., Dietrich, K., Jembrih-Simburger, D., Schreiner, M., Denis, D., Lakdar, A., Lamotte, A., 2004. A compact $\mu$-XRF spectrometer for (in situ) analyses of cultural heritage and forensic materials. Nucl. Inst. Meth. B 213, 693-698.

Vittiglio, G., Janssens, K., Vekemans, B., Adams, F., Oost, A., 1999. A compact small-beam XRF instrument for in-situ analysis of objects of historical and/or artistic value. Spectrochim. Acta Part B 54, 1697-1710. http://dx.doi.org/10.1016/S05848547(99)00100-7. 